\title{
As contribuições do Serviço Especial de Saúde Pública para a formação profissional da Enfermagem no Brasil (1942-1960)
}

\author{
The contributions of the Serviço Especial de Saúde Pública for nursing professional formation in Brazil (1942-1960) \\ Las contribuciones del Serviço Especial de Saúde Pública para la formación profesional \\ de la Enfermería en Brasil (1942-1960)
}

\author{
Rogério Dias Renovato', Maria Helena Salgado Bagnato' \\ 'Universidade Estadual de Campinas. Faculdade de Educação. Campinas, SP
}

Submissão: $30 / 11 / 2007$

Aprovação: 23/10/2008

\section{RESUMO}

O objetivo desse estudo foi conhecer e compreender as estratégias do Serviço Especial de Saúde Pública (SESP) para expandir a formação de profissionais da Enfermagem em nível superior e técnico no Brasil, entre 1942 a 1960. Utilizamos como fontes históricas a Revista do SESP e o Boletim do SESP, incluindo os números publicados a partir de 1944. A atuação do SESP junto a processos de formação de profissionais em Enfermagem, caracterizou-se pelo uso de várias estratégias como a concessão de bolsas ou o apoio financeiro e técnico para a implantação de escolas de Enfermagem no Brasil. Assim, as ações sespianas convergiram para a ascensão de um novo ethos da Enfermagem, não apenas na zona rural, como também, a Enfermagem hospitalar.

Descritores: Educação em Enfermagem; História da Enfermagem; Saúde pública.

\section{ABSTRACT}

The aim of this study was to know and comprehend the strategies of the Serviço Especial de Saúde Pública (SESP) to expand associate and higher nursing education in Brazil, between 1942 to 1960. We use as historical sources Revista do SESP and Boletim do SESP published since 1944. The performance of SESP close to processes of human resources formation in nursing was it characterized by the use of several strategies as the concession of fellowships or financial and technical support for the implantation of nursing schools in Brazil. Like this, the actions of SESP converged for the ascension of a new way of nursing, not just in the rural zone, as well as, the hospital nursing.

Descriptors: Education, nursing; History of Nursing; Public health.

\section{RESUMEN}

El objetivo de ese estudio fue conocer y comprender las estrategias del Serviço Especial de Saúde Pública (SESP) para expandir la formación de nivel superior y técnico en Brasil, desde 1942 hasta 1960. Las fuentes históricas que hemos utilizado fueron: la Revista del SESP y el Boletín del SESP, incluyendo los números publicados a partir de 1944. La actuación del SESP junto a procesos de formación de profesionales en Enfermería se ha caracterizado por el uso de varias extrategias como la conseción de becas o apoyo financiero y técnico para la implantación de escuelas de Enfermería en Brasil. Así Que, las acciones sespianas convergieron para la ascención de un nuevo ethos de la Enfermería, no sólo en la zona rural, sino la Enfermería hospitalaria.

Descriptores: Educación en Enfermería; Historia de la Enfermería; Salud pública. 


\section{INTRODUÇÃO}

O Serviço Especial de Saúde Pública (SESP) foi criado em 17 de julho de 1942, em decorrência de um acordo firmado entre os Estados Unidos e o Brasil, estabelecendo as seguintes atribuições: o saneamento do Vale do Amazonas, o preparo de profissionais para o trabalho de saúde pública e a colaboração com o então Serviço Nacional de Lepra.

A proposta norte-americana estabeleceu acordos bilaterais com países latino-americanos, dentre eles o Brasil. Estes acordos integravam um plano maior para essa área continental, iniciado na década de 30, visando ampliar a cooperação com os países do hemisfério sul. Porém, com o avanço da Segunda Guerra Mundial, a criação do SESP deveria garantir as condições sanitárias no Amazonas, e posteriormente, no Vale do Rio Doce, a fim de expandir a produção de matérias-primas para fins militares, como a borracha e minérios.

No período pós-guerra, as atividades do SESP se modificaram, tornando-se um grande prestador de serviços de saúde nas regiões visadas pelos planos desenvolvimentistas do governo brasileiro. Desse modo, o modelo de atuação deste Serviço passou a se apoiar nas estratégias de Qualificação dos trabalhadores da saúde, de educação sanitária e de construção de uma rede horizontal integrada e permanente de unidades de serviços de saúde, o Que levou a expansão desse modelo aos demais departamentos estaduais de saúde ${ }^{(1)}$.

A proposta do SESP empregou o modelo norte-americano como padrão para estabelecer uma proposta embrionária de atenção primária em saúde. Desse modo, o SESP foi uma agência especializada, assumindo uma moderna administração sanitária aos estados brasileiros, incorporando dispositivos eficazes desse modelo de regulação, como a estatística vital, a higiene infantil, a prevenção de acidentes, o controle de tuberculose e a educação sanitária $^{(1)}$.

Todavia, o modelo do SESP não se configurou como uma imposição do modelo norte-americano em solo brasileiro, e sim em uma transação de mão dupla, Que evidenciava convergências com as idéias propagadas em fóruns internacionais, bem como se coadunava com o projeto varguista de institucionalização da saúde pública no país, visto Que o SESP se estendeu em regiões pouco atingidas pela autoridade do Estado, como o Amazonas e o Nordeste, ainda sob a tutela das oligareuias locais ${ }^{(1)}$.

Assim, o objetivo desse estudo foi conhecer e compreender as estratégias implementadas pelo SESP para expandir a formação de profissionais da Enfermagem em nível superior e técnico no Brasil no período de 1942 a 1960. Em um primeiro momento, pretendemos abordar uma dessas estratégias, a concessão de bolsas para a realização de cursos de Enfermagem, principalmente nos Estados Unidos e em escolas de Enfermagem brasileiras. Em seguida, a atuação das enfermeiras do SESP, como agentes de formação de profissionais auxiliares - as visitadoras sanitárias e os auxiliares hospitalares.

E ao final, debruçar sobre o papel do SESP na colaboração e cooperação da expansão do ensino da Enfermagem no Brasil, apoiando sistematicamente a criação de novas escolas, bem como o de agente catalisador na implantação de um novo modelo de prática na profissão de Enfermagem.

\section{METODOLOGIA}

Para o recorte historiográfico, aproximamo-nos das concepções de Michel Foucault sobre a história, Que procurou problematizála, interrogando sua produção narrativa, e assim abstraindo das margens para o centro, o deslocamento do olhar, em Que tudo é histórico, e portanto, "nada do Que é humano deve escapar ao campo da visão e da expressão do historiador"(2).

Sob os auspícios do referencial foucaultiano, a história-problema, é uma forma cultural, cujos momentos estratégicos de sua problematização se caracterizam pela crítica ao essencialismo, à desnaturalização do objeto e ao privilegiamento da descontinuidade ${ }^{(2)}$. Para Foucault, é preciso trabalhar no sentido de uma "acontecimentalização". Isto é, mostrar Que tal fato não era tão necessário assim. E desse modo, repensar as descontinuidades como rupturas de evidências, Que em um dado momento da história constituíram-se como naturais, universais e necessárias.

Como fontes históricas, utilizamos a Revista do SESP e o Boletim do SESP. A publicação semestral da Revista do SESP iniciou-se em 1947 com a finalidade de divulgar os trabalhos de peseuisa realizados pelo serviço, bem como assuntos relacionados ao campo da saúde pública. A revista constituiu-se em espaço de divulgação dos trabalhos e experiências dos profissionais do SESP, e de suas concepções sobre saúde, pesQuisa em saúde e educação em saúde.

O Boletim do SESP começou a ser publicado mensalmente em 1944, com o objetivo de divulgar as ações do SESP. O compêndio de notícias do Boletim incluía desde as visitas dos profissionais de saúde aos mais variados municípios assistidos pelo SESP, como artigos sobre saúde pública, relatos das ações realizadas, até os discursos dos paraninfos das formaturas das visitadoras sanitárias.

Nesta pesquisa histórica, também utilizamos outras fontes, como a Revista de Higiene e Saúde Pública e a compilação histórica das realizações do $\mathrm{SESP}^{(3)}$, buscando, assim, "definir no próprio tecido documental, unidades, conjuntos, séries, relações ${ }^{(4) "}$.

\section{RESULTADOS E DISCUSSÃO}

Programa de Treinamento do SESP e o Serviço de Enfermagem

No período de 1942 a 1959, cerca de 518 profissionais de saúde receberam apoio do SESP para as atividades de educação inicial e continuada em solo norte-americano, sendo Que apenas 201 eram funcionários do SESP. Dentre as categorias de profissionais Que mais receberam esse suporte educativo, foram os médicos, os engenheiros e as enfermeiras ${ }^{(5)}$.

No mesmo período acima, 487 profissionais de saúde lotados no SESP receberam incentivos para formação e capacitação no Brasil. As ações do SESP também se estenderam a profissionais não vinculados ao SESP, totalizando 769 enfermeiras, médicos e assistentes sociais Que receberam ações educativas de formação, aperfeiçoamento e atualização( ${ }^{(5)}$.

O processo sistematizado de formação também alcançou os profissionais de nível técnico ou auxiliar, sendo capacitados no período de 1942 a 1959, 495 visitadoras sanitárias, 376 auxiliares hospitalares, 286 laboratoristas e 594 auxiliares de saneamento. Todos esses compunham Quadro de auxiliares do SESP. Em relação aos profissionais de nível auxiliar de outras instituições, os números 
são mais vultosos chegando a 2089 auxiliares, como auxiliares de enfermagem, de nutrição, de educação sanitária, de serviço social e de maternidade ${ }^{(5,6)}$

O empenho movido pelo SESP em aplicar políticas de formação de trabalhadores da saúde encontra fundamento na enorme carência desses profissionais em todo o Brasil, cuja solução contribuiria para o SESP atingir seus objetivos firmados no acordo bilateral Brasil - Estados Unidos.

A carência de recursos humanos colige com o ethos sespiano, Que dentre outros elementos Que o compõem, valoriza e exige uma formação profissional sólida, alimentada por cursos de especialização e de pós-graduação no exterior. O profissional sespiano seria caracterizado por uma rigidez Quase Que militar, pela valorização do trabalho em equipe, dedicação com exclusividade à saúde pública, e conduta de trabalho pautada na meritocracia $^{(7)}$.

A preocupação com a Qualificação consolidou a imagem do SESP, e estendeu sua esfera de influência nos serviços públicos de saúde, introduzindo procedimentos e valores, não apenas em seu próprio território de atuação, como também nos demais serviços estaduais e municipais, com os Quais mantinha convênio. Em suma, o SESP parecia se caracterizar como entidade detentora dos melhores profissionais de saúde, prestava assistência de saúde e profilática de boa Qualidade, e introduziu técnicas pioneiras de saneamento.

Como uma das estratégias de capacitação dos profissionais de saúde, o SESP passou a oferecer bolsas de estudos em universidades americanas, canadenses e brasileiras. A bolsa tinha duração de 1 ano para médicos, e 3 anos para enfermeiras. Neste último caso, o prazo maior da bolsa era pelo fato da mesma ser dedicada para a formação inicial, e não como curso de atualização ou aperfeiçoamento. Através dessa modalidade de bolsa, o SESP assumia todas as despesas, incluindo livros, alimentação, residência e uma Quantia mensal em dólares.

No ano de 1944, catorze jovens brasileiras receberam bolsas de estudos para realizar o curso de graduação em enfermagem na Johns Hopkins School of Nursing, Baltimore; Providence Division of the Catholic University School of Nursing Education, Washington; Washington University School of Nursing, St. Louis; Skidmore College e University of Maryland School of Nursing, Baltimore ${ }^{(5)}$.

A relação de bolsistas nos anos de 1946 a 1947 para o curso de Enfermagem incluiu Yonita Assenço Torres, Que já atuava como instrutora da Escola de Enfermagem do Estado do Rio de Janeiro, Lydia Damasceno e Yara Miranda, ambas atuando no Programa do Amazonas do SESP. Estas duas últimas passaram a realizar o curso na North Carolina University, e a primeira na Universidade de Vanderbilt ${ }^{(8)}$

No relatório de atividades referente ao ano de 1948, apareceram discriminadas dois tipos de bolsas para enfermeiras, uma relacionada ao auxílio para realização de curso de graduação em enfermagem e a outra, como auxílio para um curso de pós-graduação em saúde pública. Segundo o relatório acima, foram enviadas 22 moças para o curso básico de 3 anos e 14 para curso de pós-graduação de 1 $\mathrm{ano}^{(9)}$.

Contudo, problemas referentes ao idioma, longa separação da família, dificuldades de adaptação à vida americana, principalmente em um período de guerra, levaram à redução desse tipo de formação, passando a ocorrer em instituições brasileiras, como a Faculdade de Saúde Pública, a Escola de Enfermagem da Universidade de São Paulo e o Departamento Nacional de Saúde do Ministério da Educação e Saúde ${ }^{(10)}$. Mesmo assim, 10 médicos e 7 enfermeiros ainda receberam auxílio do SESP para realização de atualização nos Estados Unidos, praticamente um ano antes da agência se tornar fundação vinculada ao Ministério da Saúde ${ }^{(5)}$.

De 1942 a 1953, as atividades de enfermagem, inicialmente agregadas na Seção de Treinamento de Enfermagem, e depois Divisão de Enfermagem, ficaram sob a chefia de uma enfermeira americana. Com o aumento de enfermeiras diplomadas no Brasil, essas profissionais passaram a contribuir na formação de profissionais em nível técnico, organizando os primeiros cursos de auxiliares hospitalares e visitadoras sanitárias ${ }^{(1)}$.

As enfermeiras participaram ativamente do curso de formação de visitadoras sanitárias, atuando tanto na seleção do pessoal, como ministrando a maior parte do conteúdo. Para essa modalidade de formação, o SESP adotou o regime de internato, visto Que: "justifica-se esta atitude do Serviço para possibilitar melhor vigilância às alunas, maior oportunidade para educação doméstica social e moral, salvaguarda da responsabilidade moral do Serviço perante às famílias ${ }^{(12) "}$.

O curso para visitadoras sanitárias estendeu-se para outros estados, atingindo o Vale do Rio Doce, Alagoas e Bahia. Nesses estados, as enfermeiras distritais e das unidades sanitárias assumiram a responsabilidade pelo curso, o Que acarretou sobrecarga de serviço e prejuízo das atividades assistenciais A solução proposta foi retornar ao modelo clássico de cursos regulares, porém abandonando o sistema de internato, Que seria bastante dispendioso ${ }^{(3)}$.

O treinamento de auxiliares hospitalares ocorreu inicialmente no Programa do Amazonas, sendo realizado no Hospital Evandro Chagas, em Belém, e nos hospitais de Santarém e Breves. As exigências eram ter a idade entre 18 a 30 anos, bom estado de saúde e priorizar os candidatos com certificado de curso ginasial ou normal. A modalidade de internato também foi aplicada, porém os estudantes masculinos residiam fora do internato, motivo pelo Qual sua bolsa tinha valor maior.

Os primeiros cursos de auxiliares hospitalares foram realizados sob a responsabilidade de enfermeiras brasileiras e americanas, tendo também a participação de médicos e nutricionista. No entanto os cursos regulares de auxiliares hospitalares foram suspensos em 1955, a partir da regulamentação do exercício de enfermagem, passando o SESP a admitir em seus serviços hospitalares, apenas auxiliares de enfermagem com curso de 18 meses ${ }^{(11)}$.

Segundo o relatório de atividades de 1948, sete cursos para visitadoras sanitárias foram realizados no Programa do Amazonas, formando 47 profissionais, e seis cursos para auxiliares hospitalares, com a formação de 83 auxiliares. No Programa do Vale do Rio Doce, três cursos para visitadoras ocasionaram a formação de 45 profissionais $^{(9)}$.

Todo esse envolvimento do SESP na capacitação de profissionais de saúde, e no caso da Enfermagem, pode ser resumido pela fala de Pinheiro ${ }^{(13)}$, aludindo a preocupação dessa agência com a Qualificação de sua equipe, bem como o apoio multifacetado à expansão das escolas de enfermagem no Brasil:

Fosse aquele (o SESP) um Serviço brasileiro provavelmente teria 
funcionado com "enfermeiros" inapropriados, como acontecia e ainda acontece na maior parte do País; nem os americanos aceitavam mais essa hipótese. Para ter em seus serviços enfermeiras diplomadas, o SESP recrutava jovens nas áreas onde atuava e as encaminhavam a escolas de enfermagem, com bolsas de estudo, por outro lado, auxiliava as escolas com maior probabilidade de desenvolvimento $^{(13) "}$.

Contribuição do SESP para o ensino da Enfermagem no Brasil

$\mathrm{Na}$ década de 1930, com a retirada da missão de enfermeiras norte-americanas, começaram a surgir outras escolas de Enfermagem. Todavia, o reconhecimento ocorreria em conformidade ao padrão ouro da Escola Anna Nery, Que contribuiu para o alto nível de educação profissional, mas dificultou a expansão do ensino de Enfermagem no Brasil e ocasionou número deficitário dessas profissionais, situação já explicitada anteriormente ${ }^{(14)}$.

A Escola Anna Nery instituída como escola oficial enfrentou dificuldades para firmar-se como escola modelo e norteadora das diretrizes do ensino da Enfermagem. A formação da Enfermeira de Saúde Pública defendida pela escola sofreu barreiras em se firmar como paradigma principal, visto Que a expansão dos Institutos de Aposentadoria e o modelo previdenciário de Vargas favoreceram a expansão dos hospitais, marcando a transição de um modelo de prática voltado para a assistência hospitalar ${ }^{(15)}$.

Ao final dessa década, a Escola Anna Nery ingressou na Universidade do Brasil, e com a assunção da diretora Laís Netto dos Reys, outra etapa se configurou no ensino da Enfermagem. Esse período se caracterizou na luta simbólica pela hegemonia da Enfermagem entre a Anna Nery e a recém-criada Escola de Enfermagem de São Paulo, liderada por Edith Fraenkell, com a forte colaboração do SESP, Que promoveu a expansão aligeirada do ensino da Enfermagem, em todo o país.

Em outubro de 1942, a enfermeira americana Mary Elizabeth Tennant, da Fundação Rockfeller realizou investigação sobre a Enfermagem no Brasil, encaminhando seu relatório ao SESP. O relatório deveria realizar um reconhecimento cuidadoso da enfermagem brasileira:

Tal reconhecimento deveria incluir uma análise quanto as "fontes de preparo de enfermeiras", considerando o "valor do ensino ministrado" e o "número de enfermeiras Que possam(diam) ?ser preparadas”. Ademais, acrescenta o relatório, Que esse empreendimento visava também "escolher as instituições Que oferecem(ciam) maiores vantagens para o desenvolvimento de novas fontes de preparo de enfermeiras ${ }^{(16)}$ ".

O relatório alertava para o número insuficiente de enfermeiras atuando no país, cerca de 400, formadas por 3 escolas de enfermagem equiparadas ao padrão Anna Nery. A proposta da relatora enfatizava, além da criação de órgão no Ministério de Educação e Saúde, Que se responsabilizasse pelas diretrizes e estruturação do ensino da Enfermagem, como a construção de pelo menos mais Quatro escolas, sendo uma no Rio de Janeiro, outra em São Paulo, Bahia e Pará(3).

Esse documento explicitava o interesse da Fundação Rockefeller em minimizar os efeitos do Decreto 20.109/31, Que atribuía à Escola Anna Nery, o modelo oficial de escola padrão, para se obter a eQuiparação, sem considerar, entretanto, Que a diretora Laís Netto dos Reys da Escola Anna Nery também já havia pronunciado sua preocupação em difundir o ensino da Enfermagem no Brasil, como também a regulamentação profissional dos auxiliares de enfermagem, tema polêmico e foco de muitas divergências entre as enfermeiras ${ }^{(16)}$.

Como decorrência do relatório, o SESP criou em sua estrutura, em novembro de 1942 a Divisão de Enfermagem, tendo como uma das atribuições: "estudar as áreas interessadas em atividades de educação em enfermagem, determinando especialmente, as possibilidades que o SESP pode contribuir com serviços, com ajuda financeira ou com ambas ${ }^{(3) "}$.

A enfermeira Claire Louise Kienenger, primeira diretora da Escola Anna Nery, foi enviada como interlocutora entre as enfermeiras brasileiras e o SESP, todavia sua missão não teve êxito, encontrando resistência da diretora Laís Netto Reys, Que impediu QualQuer interferência da enfermeira americana em sua gestão.

Kienenger se reportava ao discurso patriótico, enaltecendo o papel da enfermeira na guerra, e ao mesmo tempo denunciava a escassez dessa profissional no Brasil, porém sua fala exaltava a superioridade americana em assuntos sanitários, o Que justificaria sua intromissão colaborativa nos assuntos da enfermagem, como a vistoria das escolas de enfermagem Que almejassem a equiparação ao padrão oficial, responsabilidade legal atribuída à Escola Anna Nery ${ }^{(17)}$.

Em 1943, Miss Kienenger retornou aos Estados Unidos, sendo substituída por Gertrude Hodgman encerrando um período de embates acadêmicos pelo poder de enunciar os novos rumos da enfermagem brasileira, uma vez Que a diretora Laís não se submetia ao comando da representante americana do SESP. Desse modo, estabeleceu-se um espírito de antagonismo entre a Escola e o SESP ocasionado por um pequeno grupo de instrutoras e a própria diretora $^{(3)}$.

Contudo, mesmo diante dessa situação problemática, foi traçada uma política amistosa, mantendo ainda relações estreitas, mas implementando outras ações de intercâmbios e cooperação com instituições e lideranças de outros estados, como o Estado de São Paulo.

Após o relatório de Miss Tennant, foi proposta a criação da Escola de Enfermagem de São Paulo, tendo como diretora a exsuperintendente do Serviço de Enfermeiras do Departamento Nacional de Saúde Pública, a enfermeira Edith de Magalhães Fraenkel. A proposta do curso já havia sido apresentada à representante da Fundação Rockfeller Mary Tennant, em maio de 1940 pelo interventor federal do Estado de São Paulo, Dr. Adhemar de Barros, e pelo diretor da Faculdade de Higiene e Saúde Pública, o médico Geraldo Horácio de Paula Souza ${ }^{(13)}$.

A Fundação Rockfeller contribuiu com o processo de capacitação da enfermeira Edith Fraenkel, bem como concedeu bolsas de estudos a seis educadoras sanitárias para realização do curso de Enfermagem na Universidade de Toronto. Esse grupo foi chamado de As Damas de Toronto composto por Maria Rosa S. Pinheiro, Zilda de Almeida Carvalho, Glete de Alcântara e Lucila Jardim. Além dessas, Edith Fraenkel obteve bolsa de estudos, para observação de Escolas de Enfermagem dos Estados Unidos e do Canadá(13).

Para Almeida Filho ${ }^{(16)}$, a formação de docentes no exterior constituiu-se em estratégia para formar um grupo cuja competência seria reconhecida no ambiente científico da época, sendo dotado de um discurso autorizado e capaz de se contrapor ao modelo de enfermagem da Escola Anna Nery. 
O apoio do SESP ocorreu a partir de seu auxílio na construção do edifício Que abrigaria a futura Escola de Enfermagem de São Paulo. O prédio começou a ser construído em novembro de 1943, sob a responsabilidade da firma Lindenberg \& Assumption. Em 31 de outubro de 1947, o prédio foi inaugurado. O SESP participou com $60 \%$ do custo total da obra e o Estado, com 35\%. A Fundação Rockfeller participou na aQuisição de equipamentos e mobiliário ${ }^{(3)}$.

No Boletim do SESP, foram descritos detalhes do projeto arQuitetônico da Escola de Enfermagem:

Terá Quatro andares, devendo servir de residência a 184 estudantes de enfermagem. As alunas Que estiverem iniciando o curso ficarão alojadas em Quartos de três camas, e as mais adiantadas em Quartos de uma só cama. Haverá ainda apartamentos para o pessoal da direção e funcionárias. Três salas de aula, dois refeitórios (um no terraço), laboratórios de Química, biologia, anatomia e biblioteca, salas sociais, auditorium, sala de recreios e de jogos - são outras dependências. O edifício terá abrigo antiaéreo e instalações contra incêndios. $\mathrm{O}$ vidro é largamente usado: nada menos Que 1.300 metros de Quadrados de vidro. Outros dados interessantes: 1.000 metros Quadrados de azulejos, dois elevadores, 380 estacas com o comprimento total de 3.300 metros, 2.000 metros Quadrados de esquadrias, 1.000 metros de encanamento nas instalações de água. Todos os móveis foram desenhados especialmente pelo arquiteto $^{(18)}$.

O imponente edifício Que lembrava um navio foi apelidado na época de Montenegro Maru, provavelmente em referência ao diretor da Faculdade de Medicina da Universidade de São Paulo, Benedito Montenegro, também coordenador das atividades de construção do prédio.

E no dia da sua inauguração, foi colocada uma placa comemorativa com os seguintes dizeres: "M.E.S. Serviço Especial de Saúde Pública. Esta Escola de Enfermagem, Símbolo de uma sã política de boa vizinhança, foi construída pelos governos dos Estados Unidos do Brasil e dos Estados Unidos da América, com a cooperação do Governo do Estado do São Paulo ${ }^{(13)}$.

O discurso acima encontra ressonâncias em Carvalho apud Oguisso e Freitas, mencionando aQui especificamente a Fundação Rockfeller: influência da Fundação Rockfeller na criação da Escola, e Que possivelmente, sem sua interferência direta, insistente e persistente, e sem o auxílio financeiro e técnico colocado à disposição da futura entidade educacional, poderia ter havido um atraso de, pelo menos dez anos, num empreendimento já tardiamente iniciado, se considerando o desenvolvimento do ensino da enfermagem em outros países, e mesmo no Brasil e no próprio Estado de São Paulo(19)".

Com a criação da Escola de Enfermagem de São Paulo e o apoio do SESP, estabeleceu-se um novo modelo de formação de enfermeiras, não abandonando a formação da enfermagem de saúde pública, mas atendendo um outro campo Que crescia - a assistência hospitalar. Assim, "o programa da Escola de Enfermagem visava preparar a "verdadeira enfermeira profissional", cujos conhecimentos técnicos, e, embora fosse uma "arte", não poderia prescindir do aprendizado sob bases científicas ${ }^{(20)}$.

Nos primeiros anos da Escola de Enfermagem de São Paulo, o SESP passou a recrutar alunas em Curitiba, Porto Alegre, Salvador, Aracaju, Recife, Fortaleza e Belém. O SESP oferecia bolsas de estudo e assegurava uma Quantia correspondente a Quinhentos dólares, Que auxiliavam na assistência daQuelas consideradas extremamente pobres, em caráter emergencial. O processo de captação promovido pelo SESP fortaleceu o papel da Escola, como centro formador de enfermagem, e também contribuiu para ampliar o número dessas profissionais no país ${ }^{(16)}$.

Em 1944, a Escola contava em seu Quadro discente, com trinta alunas bolsistas do SESP, oriundas de nove estados da federação, a saber: Amazonas, Pará, Ceará, Sergipe, Bahia, Paraná, Santa Catarina, Rio Grande do Sul e São Paulo(16).

Além da Escola de Enfermagem de São Paulo, o SESP contribuiu com outras escolas, dentre elas a Escola de Enfermagem do Estado do Rio de Janeiro, localizada na cidade de Niterói. Inicialmente, a escola funcionou provisoriamente em dois andares do Sanatório Azevedo Lima até a sua transferência para prédio próprio ${ }^{(21)}$.

O SESP apoiou a criação e a instalação da escola. A primeira turma foi composta de 22 moças provenientes dos estados do Nordeste, São Paulo, Minas Gerais, além do Rio de Janeiro. Para o ensino de enfermagem na escola, foi adotado o sistema de internato. A residência das ingressantes era composta de sala de recepção e de leitura, locais de recreio e esportes.

O curso seria ministrado em três anos, sendo dividido em Quatro períodos: o preparatório, o júnior, o intermediário e o sênior. Os professores da parte teórica pertenciam à Faculdade Fluminense de Medicina, e as aulas de prática de enfermagem seriam realizadas por enfermeiras diplomadas na Anna Nery. O primeiro grupo de alunas da escola, oriundas do Amazonas e do Vale do Rio Doce, receberam curso de formação para visitadoras sanitárias, sendo sustentadas financeiramente pelo SESP.

No transcorrer do período de 1942 a 1960, o SESP contribuiu ativamente para o ensino de enfermagem (Quadro I). Porém, seu apoio também se materializou nas discussões sobre o papel da Escola Anna Nery na eQuiparação de outras escolas, bem como na legislação sobre o curso de auxiliar de enfermagem.

O SESP desenvolveu estratégias para minimizar o papel da Escola Anna Nery, como podemos ver na fala do Dr. Sérvulo Lima, superintendente do SESP alertando Que a Anna Nery não se mostrava mais tão eficaz em assegurar o alto padrão das escolas de enfermagem. Assim, o SESP começou a interferir em algumas atribuições específicas da escola oficial, como por exemplo, a indicação dos nomes das enfermeiras responsáveis pelas inspeções das novas escolas de enfermagem ${ }^{(16)}$.

O SESP também participou das reuniões das diretoras das Escolas de Enfermagem, realizadas sob a direção de Laís Netto Reys no período de 1943 a 1945. Nessas reuniões, as temáticas eram variadas, como a inspeção das escolas, os estágios e aulas práticas, a regulamentação da profissão, o currículo mínimo. Ao todo foram cinco reuniões nesse período, contando com a participação dominante das Escolas de Enfermagem localizadas nas cidades do Rio de Janeiro e São Paulo ${ }^{(22)}$.

O SESP, mais uma vez a partir de sua representante Ella Haisejeader, atuou de forma decisiva na regularização do curso auxiliar de enfermagem. A enfermeira americana foi convidada pela Associação Brasileira de Enfermeiras Diplomadas (ABED) para presidir a comissão Que concluiria os estudos acerca da regulamentação dos cursos de auxiliares de enfermagem, personificando, assim, o discurso autorizado das enfermeiras americanas $^{(22)}$. 


\begin{tabular}{|c|c|}
\hline Escolas de Enfermagem & Tipo de auxilio prestado pelo SESP \\
\hline 1- Escola de Enfermagem Anna Nery. & $\begin{array}{l}\text { Apoio na realização do dia da Enfermeira de Saúde Pública; custeio de } \\
\text { viagens aéreas para candidatas de outros estados ao processo de seleção; } \\
\text { concessão de bolsas para as instrutoras nos Estados Unidos. }\end{array}$ \\
\hline 2- Escola de Enfermagem de São Paulo & $\begin{array}{l}\text { Auxílio na construção do prédio da escola; apoio financeiro na aQuisição } \\
\text { de material e na elaboração das normas e regulamentos; cessão de bolsas } \\
\text { para candidatas ingressantes na escola. }\end{array}$ \\
\hline $\begin{array}{l}\text { 3- Escola de Enfermagem Rachel Haddock Lobo, Rio de } \\
\text { Janeiro }\end{array}$ & $\begin{array}{l}\text { Preparação do regulamento e das normas administrativas e técnicas; } \\
\text { organização dos campos de estágio }\end{array}$ \\
\hline 4- Escola de Enfermagem do Estado do Rio de Janeiro & $\begin{array}{l}\text { Cessão de enfermeiras do SESP para atividades de ensino; auxílio } \\
\text { financeiro para reforma do prédio da escola, aquisição de equipamento e } \\
\text { pagamento de salários das enfermeiras-docentes; bolsas de estudos para } \\
\text { as alunas. }\end{array}$ \\
\hline 5- Escola de Enfermagem de Manaus & $\begin{array}{l}\text { Organização e estruturação da escola; construção de prédio para escola; } \\
\text { aQuisição de eQuipamentos e instalações. }\end{array}$ \\
\hline 6- Escola de Enfermagem de Porto Alegre & $\begin{array}{l}\text { Organização e estruturação da escola; sustento financeiro de algumas } \\
\text { docentes-enfermeiras. }\end{array}$ \\
\hline 7- Escola de Enfermagem Carlos Chagas, Belo Horizonte & $\begin{array}{l}\text { Assistência técnica e financeira; cessão de duas enfermeiras do SESP para } \\
\text { as atividades de ensino; suplementação financeira dos salários de algumas } \\
\text { docentes-enfermeiras. }\end{array}$ \\
\hline $\begin{array}{l}\text { 8- Escola de Enfermagem Ermantino Beraldo, Juiz de } \\
\text { Fora. }\end{array}$ & $\begin{array}{l}\text { Cessão de uma enfermeira do SESP para as atividades de ensino; } \\
\text { suplementação financeira dos salários de algumas docentes-enfermeiras. }\end{array}$ \\
\hline $\begin{array}{l}\text { 9- Escolas de Enfermagem Católicas - Escola Luiza } \\
\text { Marillac, Rio de laneiro e a Escola Paulista de } \\
\text { Enfermagem, São Paulo }\end{array}$ & $\begin{array}{l}\text { Apoio financeiro para estudo das escolas católicas de enfermagem no } \\
\text { Brasil realizado por duas religiosas americanas durante seis meses; } \\
\text { concessão de bolsas de estudo em escolas de enfermagem americanas }\end{array}$ \\
\hline $\begin{array}{l}\text { 10- Escola de Enfermagem Hugo Werneck, Belo } \\
\text { Horizonte }\end{array}$ & $\begin{array}{l}\text { Auxílio financeiro para realização de estágio em enfermagem de saúde } \\
\text { pública. }\end{array}$ \\
\hline 11- Escola de Enfermagem da Bahia & $\begin{array}{l}\text { Organização e estruturação da escola, suplementação dos salários das } \\
\text { enfermeiras-docentes. }\end{array}$ \\
\hline 12- Escola de Enfermagem de Pernambuco & $\begin{array}{l}\text { Organização e estruturação da escola; apoio financeiro para o pagamento } \\
\text { dos salários da diretora da escola, Quatro enfermeiras assistentes e } \\
\text { algumas enfermeiras-docentes. }\end{array}$ \\
\hline $\begin{array}{l}\text { 13- Escola de Enfermagem da Cruz Vermelha, Rio de } \\
\text { Janeiro }\end{array}$ & Auxílio não especificado \\
\hline $\begin{array}{l}\text { 14- Escola de Enfermagem São Vicente de Paulo, } \\
\text { Goiânia }\end{array}$ & Auxílio não especificado \\
\hline $\begin{array}{l}\text { 15- Escola de Enfermagem de Passo Fundo, Rio Grande } \\
\text { do Sul }\end{array}$ & Auxílio não especificado \\
\hline
\end{tabular}

Quadro 1. Auxílios realizados pelo SESP em relação às Escolas de Enfermagem Brasileiras.

\section{CONSIDERAÇÕES FINAIS}

As contribuições do SESP para a formação da Enfermagem pautaram-se por várias estratégias como a concessão de bolsas ou o apoio financeiro e técnico para a implantação de escolas de Enfermagem no Brasil. O motivo de tais articulações fundamentavase na carência de enfermeiras, não somente para os serviços de saúde brasileiros em expansão, mas para o próprio modelo sespiano, Que tinha na Enfermagem, um dos pilares de suas ações.

Com a expansão do SESP, seu ethos também influenciou o modo de atuação da Enfermagem, tendo como foco a busca pela excelência na capacitação, o aperfeiçoamento continuado e a práxis alicerçada na saber técnico e científico. Sua influência atingiu as Escolas de Enfermagem através de assessorias e suportes técnicos ofertados pelo SESP, Que delimitaram os conteúdos curriculares e as normas para os estágios e a identidade da nova enfermagem.

O SESP não trouxe consigo apenas o modelo norte-americano de assistência em saúde, mas também sofreu interferências da realidade brasileira, e contribuiu para o projeto varguista de integração nacional, levando todo o cabedal de nacionalidade e civismo aos espaços geográficos ainda abandonados, como o Amazonas. Com isso, o SESP fomentou ações curativas e preventivas em saúde, com o auxílio indispensável da Enfermagem, Que contribuiu com a formação de auxiliares, os principais responsáveis pela capilarização das concepções sespianas de educação e saúde no sertão brasileiro.

A proposta do SESP para a Enfermagem contrapôs-se ao modelo annanery. Assim, através do apoio sistematizado para a implantação de novas Escolas de Enfermagem, o SESP contribuiu na ruptura do poder simbólico da Anna Nery, incentivando e fortalecendo o papel de outras escolas, bem como de outras enfermeiras, o Que convergiu para a assunção de um novo ethos da Enfermagem, não apenas na zona rural, como também em uma área de grande expansão, a Enfermagem em ambiente hospitalar. 


\section{REFERÊNCIAS}

1. Campos ALV. Políticas internacionais de Saúde na Era Vargas: o Serviço Especial de Saúde Pública, 1942- 1960. Rio de Janeiro: Fiocruz; 2006.

2. Rago M. O efeito-Foucault na historiografia brasileira. Tempo Social 1995; 7(1-2): 67-82.

3. Bastos NCB. SESP/FSESP, Evolução história: 1942-1991. Recife: Comunicarte; 1993.

4. Foucault M. A Arqueologia do saber. $7^{\text {a. }}$ ed. Rio de Ianeiro: Forense Universitária; 2005.

5. Bastos NCB. Programa de Formação de Recursos Humanos para a Saúde: 38 anos de experiência da Fundação Serviços de Saúde Pública 1942-1980. Rev Fundação SESP 1984; 29(1): 3-54.

6. Silva OJ, Bastos NCB, Rios IA, Rivera SF, Lundy HH. Preparação de técnicos e auxilares de educação sanitária. Rev SESP 1954; 6(2): 497-507.

7. Peçanha AMM. Fundação Serviço Especial de Saúde Pública FSESP: um estudo de desenvolvimento institucional [dissertação]. Rio de Janeiro (RI): Fundação Getúlio Vargas; 1976.

8. Serviço Especial de Saúde Pública. Boletim do SESP 1946; 40: $1-12$.

9. Serviço Especial de Saúde Pública. Boletim do SESP 1948; (esp): 1-32.

10. Moraes NLA, Silva OJ. Contribuição do Serviço Especial de Saúde Pública e do Instituto de Assuntos Interamericanos à formação de técnicos. Rev Higiene Saúde Pública 1948; 2,3,4: 141-7.

11. Alvim EF. Quinze anos de enfermagem no Serviço Especial de Saúde Pública. Rev Bras Enferm 1959; 12(2): 143-59.

12. Moura N, Sá M. Formação de visitadoras sanitárias e auxiliares hospitalares para os distritos sanitários do S.E.S.P. no Programa da Amazônia. Rev Higiene Saúde Pública 1948; (2,3,4): 209 41.

13. Pinheiro MRS. Histórico da Escola de Enfermagem da Universidade de São Paulo. Rev Esc Enferm USP 1967; I(1): 3-47.

14. Baptista SS, Barreira IA. Condições de Surgimento das Escolas de Enfermagem Brasileiras (1890-1960). Reva Alternativa Enferm I997; I (2): 4-17.

15. Barreira IA. Transformações da prática da Enfermagem nos anos 30. Rev Bras Enferm 1999; 52 (1):129-43.

16. Almeida Filho AJ. A Escola Anna Nery (EAN) no "front" do campo de educação em enfermagem e o (re)alinhamento de posições de poder (1931-1949) [tese]. Rio de Janeiro (RI): Escola Anna Nery, Universidade Federal do Rio de Janeiro; 2004.

17. Barreira IA, Baptista SS. A (Re)Configuração do Campo da Enfermagem durante o Estado Novo (1937-1945). Rev Bras Enferm 2002; 55(2): 205-16.

18. Serviço Especial de Saúde Pública. Boletim do SESP 1944; 9:1-8.

19. Oguisso T, Freitas GF. Ensino e pesQuisa sobre história da Enfermagem na graduação e pós-graduação da Escola de Enfermagem, da Universidade de São Paulo. Rev Pesquisa: Cuidado é Fundamental 2005; 9(1/2): 79-91.

20. Castro Santos LA, Faria LR. A cooperação internacional e a enfermagem de saúde pública no Rio de Janeiro e São Paulo. Horizontes 2004; 22(2): 123-50.

21. Serviço Especial de Saúde Pública. Boletim do SESP 1945; 22:1-12.

22. Almeida Filho AJ, Santos TCF, Baptista SS, Lourenço LHSC. Reunião de Diretoras de Escolas de Enfermagem: um cenário de lutas simbólicas no campo da educação em Enfermagem (1943-1945). Texto Contexto Enferm 2005; 14(4): 528-36. 